\title{
A educação pós-pandemia: uma análise a partir da desigualdade educacional
}

\section{Post-pandemic education: an analysis based on educational inequality}

\author{
Clóvis Trezzi \\ Doutor em educação \\ Universidade La Salle \\ Canoas, RS - Brasil \\ clovis.trezzi@unilasalle.edu.br
}

Resumo: Este artigo, escrito em forma de ensaio, tem por objetivo analisar os possíveis reflexos da pandemia de Covid-19 sobre a educação brasileira. Partindo da história da educação moderna, surgida no século XVII, o artigo mostra que assim como naquele período, que era um momento de crise, ocorreu uma revolução na educação, este momento é propício para mudanças. Partindo da pergunta de Dubet (2004) sobre o que é uma escola justa, o artigo defende a ideia de que antes de qualquer mudança na estrutura da escola brasileira, a pandemia de Covid-19 deve levar a uma reflexão sobre a justiça educacional no Brasil. Conclui que simples mudanças na estrutura da escola visando a sua modernização podem ser mais excludentes do que inclusivas.

Palavras-chave: Pandemia. Escola justa. Inclusão.

Abstract: This article, written as an essay, aims to analyze the possible reflexes of the Covid-19 pandemic on Brazilian education. Starting from the history of modern education, which emerged in the 17 th century, the article shows that just as in that period, which was a time of crisis, there was a revolution in education, this time is propitious for changes. Based on Dubet's (2004) question about what a fair school is, the article defends the idea that, before any change in the structure of the Brazilian school, the Covid-19 pandemic should lead to a reflection on what educational justice in Brazil. It concludes that simple changes in the school structure aiming at its modernization may be more excluding than inclusive.

Keywords: Pandemic. Fair school. Inclusion.

Cite como

(ABNT NBR 6023:2018)

TREZZI, Clóvis. A educação pós-pandemia: uma análise a partir da desigualdade educacional. Dialogia, São Paulo, n. 37, p. 1-14, e18268, jan./abr. 2021. Disponível em: https://doi.org/10.5585/dialogia.n37.18268

American Psychological Association (APA)

Trezzi, C. (2021, jan./abr.). A educação pós-pandemia: uma análise a partir da desigualdade educacional. Dialogia, São Paulo, 37 , p. 1-14, e18268. https://doi.org/10.5585/dialogia.n37.18268. 


\section{Introdução}

Este artigo, em formato de ensaio, pretende analisar possíveis reflexos da pandemia de Covid-19 sobre a educação brasileira.Considera-se que para isso é preciso mencionar os problemas enfrentados pela educação no Brasil, que se refletem principalmente nos baixos índices de desempenho dos estudantes, mas também, de forma concreta, nas políticas públicas adotadas pelo país.

Normalmente, uma situação que já é ruim tende a se agravar quando aparece o inesperado. No caso atual, a pandemia de Covid-19 fez com que a realidade fosse repensada em âmbito mundial. Cunhou-se a expressão "novo normal", que passou a fazer parte da linguagem corrente para designar o novo modo de viver no período pós-pandemia. Além disso, sentimentos e necessidades que estavam latentes vieram à tona; mudanças que não ocorreriam senão daqui a vários anos passaram a ser cogitadas em caráter de urgência. A novidade da pandemia alterou até o comportamento das pessoas e das instituições.

Este artigo faz uma abordagem hermenêutica deste momento, relacionando-o com o nascimento da pedagogia moderna, no século XVII. Mostra que a grande revolução educacional daquele século ocorreu em um período de extrema necessidade e de crise, não apenas educacional, mas também de saúde pública e de fome. Partindo da pergunta de Dubet (2004): "O que é uma escola justa?”, o artigo quer mostrar que momentos de crise são propícios para pensar o futuro, assim como aconteceu no século XVII.

Neste estudo, a revisão histórica está baseada em historiadores que analisaram a educação na virada do século XVII para XVIII, de maneira especial Gauthier (2014) e Manacorda (2010). Deste período, emerge o pensamento pedagógico de La Salle (2012), pedagogo que é considerado por Gauthier (2014) como um dos fundadores da pedagogia moderna.

A metodologia hermenêutica permite transpor para o momento em que vivemos os ideais educacionais daquele período histórico. Assim, o artigo apresenta, como abertura, um breve relato das mudanças acontecidas na educação do século XVII e, partindo daí, passa a discutir a atual crise de educação no Brasil, agravada pela pandemia de Covid-19. O pano de fundo é o conceito de escola justa de Dubet (2004). O objetivo é analisar os possíveis reflexos da pandemia sobre a educação brasileira, defendendo a ideia de que o Brasil precisa antes de tudo pensar em uma escola que seja justa e inclusiva, e não apenas contar com mudanças pontuais como a introdução de novas tecnologias. 


\section{A crise do século XVII e as mudanças na educação}

O século XVII foi fundamental para a consolidação da Modernidade, especialmente para a educação e a ciência, e disso o sabemos de sobra pelos relatos de historiadores, que serão apresentados e discutidos na sequência. No chamado século do método diversas atividades humanas, como a educação, ganharam contornos científicos. Uma pergunta importante, que ajuda a compreender esse fenômeno, é: o que motivou esse processo?

Historiadores ajudam a encontrar respostas. Fazemos aqui, em linhas gerais, um pequeno apanhado de ideias acerca das mudanças ocorridas naquele século. Gauthier (2014) relata a evolução do pensamento, que fez com que a educação passasse a ser pensada e organizada: "É como se uma reviravolta de mentalidades tivesse ocorrido sobre a maneira de fazer a escola" (GAUTHIER, 2014, p. 106). Usando como modelo a pedagogia de La Salle, sacerdote e educador francês (1651-1719), fundador do Instituto dos Irmãos das Escolas Cristãs, Gauthier compara a escola que existia até então - ensino individual, sem método, sem a devida valorização do professor, com professores despreparados para o ofício - com o novo modelo das Escolas Cristãs - ensino simultâneo, com um método de ensino, professores formados para a função de ensinar, uma escola organizada (GAUTHIER, 2014, p. 108). O modelo das Escolas Cristãs de La Salle tornou-se o padrão da escola moderna nos séculos seguintes, ainda que com a Revolução Francesa a educação tenha se tornado laica.

Manacorda (2010) mostra a influência da crise gerada pelo humanismo renascentista, que trouxe à luz uma nova concepção de ser humano. Ao lado de Ariès (2015), Manacorda mostra a passagem de uma visão negativa de ser humano e de uma inexistência da infância para uma visão positiva. Com essa nova compreensão, o ser humano deixa de depender em tudo de Deus e passa a ter responsabilidade sobre as suas decisões. Essa linha de pensamento influenciou a religião, com a Reforma e a Contrar reforma. Influenciou também a educação com o surgimento da ideia, da qual Comenius e La Salle são precursores na modernidade, de que esta deveria atender a todos, independentemente de sexo, religião ou condição social. Mudou também o mundo, no sentido de que foi o despertar para a necessidade de cuidado com o próprio ser humano.

Hengemüle (2007) mostra a sucessão de crises que atingiram a população entre os séculos XVI e XVIII. Os novos paradigmas (principalmente científicos, econômicos e religiosos) afetaram a vida da sociedade, provocando alterações na vida das cidades: êxodo rural, inchaço urbano, desemprego, violência. Tudo isso associado a outros fatores, como a falta de higiene e de saneamento básico, a pobreza e a falta de atenção à população fizeram com que houvesse uma verdadeira epidemia de pobreza e miséria. De acordo com Fiévet (2001), apenas em uma grande 
seca no inverno de 1693/1694 morreram na França cerca de dois milhões de pessoas, a grande maioria em situação de pobreza. Essa e outras realidades despertaram para o papel social da educação, inclusive no combate à violência. Charles Démia (1637-1689) dizia que abrir uma escola significava fechar uma prisão (GAUTHIER, 2014, p. 111). Para La Salle (2012, p. 196), os meninos que não vão à escola "nunca serão aptos a emprego nenhum, por não saberem ler e escrever". Considerava necessário convencer os pais de que a criança "sabendo ler e escrever, é capaz de tudo" (LA SALLE, 2012, p. 197). Isso mostra que a consciência do papel social da educação começava a ser construída.

Surgiu naquele século um modelo de escola que desafiou o modelo até então tradicional. Uma escola que "possa ensinar até cem alunos simultaneamente com um trabalho dez vezes menor do que o atualmente necessário para ensinar apenas um" (COMENIUS, 2016, p. 110). Esta foi a grande revolução educacional do século XVII, que iniciou todo o processo de evolução da educação que continuou acontecendo até o final do século XX. Tanto Gauthier (2014) quanto Manacorda (2010) e Ariès (2015) apresentam as Escolas Cristãs de La Salle como as principais representantes desse movimento progressista que deu origem a toda a pedagogia moderna. Se, como diz Gauthier (2014, p. 102), pedagogia é "uma reflexão consciente e ordenada sobre a maneira de fazer e organizar a classe", então está claro que esta nasceu naquele momento, quando se começou a pensar a escola. Portanto, toda a educação posterior é reflexo daquela que nasceu naquele momento de crise e mudança.

\section{A crise de educação no Brasil}

É importante perceber que a história é dinâmica. Assim, da mesma forma como aconteceu no distante século XVII, no nosso tempo continuam ocorrendo mudanças de paradigma, remetendo ao que Santos (1995) chama de "paradigma emergente". Essas mudanças levam a novas compreensões sobre antigos conceitos, como o de família, de política, de escola. E as novas compreensões podem levar a crises de pensamento, pois um dos pilares das instituições é a tradição. Logo, mudanças de conceito ou de compreensão costumam ser vistas com cautela.

As mudanças de paradigma relatadas por Santos (1995) também estão relacionadas a novas compreensões sobre o papel da escola. A crise de educação no Brasil não é conceitual, pelo menos não no sentido de se compreender o conceito de educação, e por isso mesmo quando se fala aqui em novas compreensões sobre a escola se que falar em mudanças mais na forma de a escola atender as necessidades da sociedade e com ela interagir do que propriamente de conceito. E essas 
mudanças acabarão ocorrendo a despeito da crise anteriormente mencionada, ou talvez por causa dela.

Os problemas educacionais no Brasil têm fundo institucional. Como exemplo, temos a questão do direito à educação pública, laica e gratuita. Ele surgiu com a primeira Constituição Republicana de 1891, mas foi somente com a Constituição de 1988 que foi amplamente garantido a todos o direito à educação gratuita e financiada pelo Estado. A partir desta Carta Magna, outras leis foram incorporadas ratificando o direito à educação. Destacam-se o Estatuto da Criança e do Adolescente e a Lei de Diretrizes e Bases da Educação Nacional (Lei 9394/96) e, mais recentemente, o Plano Nacional de Educação 2014-2024.

O fato de a democracia e a garantia legal dos direitos do cidadão no Brasil serem tão recentes faz com que o país ainda seja imaturo no trato com os mesmos direitos. Problemas políticos à parte, para que a garantia legal de um direito se concretize, é necessário que o país amadureça seu projeto de nação. Para Bobbio, isso é claro:

O problema fundamental em relação aos direitos do homem, hoje, não é tanto o de justificá-los, mas o de protegê-los. Trata-se de um problema não filosófico, mas político. É inegável que existe uma crise dos fundamentos. Não se trata de encontrar o fundamento absoluto — empreendimento sublime, porém desesperado — , mas de buscar, em cada caso concreto, os vários fundamentos possíveis. (BOBBIO, 2004, p. 23 24).

A compreensão de que o direito constitucional à educação de qualidade não é garantia de igualdade de acesso à escola afeta diretamente a ação pedagógica e a experiência de escola. Um exemplo disso são os dois Planos Nacionais de Educação que, em consonância com a UNESCO, tentam de maneira mais concreta fazer com que haja uma aproximação entre o que está garantido por lei e o que chega ao alcance da população. Mesmo assim, as metas propostas pelos planos não têm sido atingidas, exceto algumas poucas - e parcialmente.

Falando do sistema educacional da França, Dubet (2004) questiona sobre o que faz uma escola ser considerada justa - compreendendo não a unidade escolar, mas o sistema. Segundo ele, para as sociedades democráticas "a escola é justa porque cada um pode obter sucesso nela em função de seu trabalho e de suas qualidades” (DUBET, 2004, p. 541). Contudo, na França, segundo ele, a escola só se tornou justa quando permitiu que "todos os alunos ingressassem na mesma competição" (DUBET, 2004, p. 541). Ou seja, o princípio da justiça na escola está na universalidade de acesso e na igualdade de condições; para Dubet, está no ingresso e não na saída.

No caso do Brasil, este conceito não é suficiente. Segundo o relatório "Pobreza na Infância e na Adolescência" (UNICEF, 2019), no Brasil 20,3\% das crianças e dos adolescentes de 4 a 17 
anos têm o direito à educação violado. No total, cerca de 2,8 milhões de crianças e adolescentes em idade escolar estão fora da escola e, de acordo com dados do Censo Escolar 2018, o índice médio de evasão escolar é de 3\%. Portanto, pensar em escola justa no Brasil é ir além da garantia de ingresso: é preciso também pensar condições que assegurem a possibilidade de permanência.

\section{O impasse e os impactos da Covid-19: o ensino remoto e a discussão sobre o Homeschooling}

Se em tempos normais é difícil para o Estado garantir o direito constitucional à educação, em situações excepcionais como a pandemia de Covid-19 isso tende a se acentuar, especialmente com o longo período de estudos domiciliares. Estes se transformam em um dilema, pois se por um lado representam o único formato possível em um tempo em que as escolas estão impedidas de receber os alunos, por outro lado acentuam as desigualdades, especialmente entre quem estuda em escola pública e em escola privada, reforçando ainda o risco de aumentar o desinteresse pela escola.

Apesar disso, concretamente falando, os anos de 2020/2021 representam, mais do que uma crise, um período de oportunidades para a educação brasileira. É certo que o começo inesperado da pandemia, quando as escolas estavam se organizando ou estavam organizadas para as atividades, cada região do Brasil em um ponto distinto do ano letivo, foi um golpe. Nesse momento muitas escolas perceberam que precisavam de um elemento do qual não dispunham: capacidade para atendimento remoto. Mais uma vez escancarou-se a desigualdade e a crise: as poucas escolas, privadas, que estavam equipadas ou que conseguiram se organizar rapidamente, saíram na frente.

Este fator em si se apresenta como negativo porque, além de prejudicial à formação das crianças e adolescentes, ainda mostra o abismo que existe entre a realidade das escolas dos pobres e das escolas dos ricos. De acordo com o Anuário Brasileiro da Educação Básica 2020 (TODOS PELA EDUCAÇÃO, 2020), apenas 3,2\% dos alunos mais pobres têm aprendizado adequado em matemática ao final do ensino médio contra $45,7 \%$ dos mais ricos; esta diferença tende a piorar, uma vez que as escolas privadas, ainda que muitas delas de forma precária, continuaram com as aulas online logo na primeira semana de pandemia, enquanto que em alguns estados e municípios os alunos ficaram até quatro ou cinco meses sem aulas.

Se por um lado a pandemia fortaleceu a desigualdade, por outro lado tornou mais patente quais são os pontos fracos da educação brasileira e mostrou caminhos para sair da crise. Demonstraremos, agora, que a simples adoção de medidas paliativas pode simplesmente mascarar o problema e, consequentemente, agravá-lo. As lições da Covid-19 não se restringem à adoção de 
novos modelos de escola ou de novos processos pedagógicos. Estes, inevitavelmente, acabarão acontecendo.

Parece claro, após o início da pandemia, que há uma defasagem tecnológica generalizada na escola brasileira, o que só piora a situação do Brasil em relação a outros países - embora, em 2020, a maioria dos países tenha percebido que a educação não recebeu a atenção dispensada a outros setores da sociedade e da economia.

Portanto, o que for dito aqui em relação a esse assunto será mera repetição do que se pode encontrar em outras discussões: a escola precisa ser mais tecnológica, estar aberta para o virtual, investir mais em atividades online, preparar os professores para o uso das tecnologias de informação e comunicação, incrementar os processos de gestão para aprender a lidar com o novo e inesperado, deixar de ser analógica para tornar-se digital, e assim por diante. Tudo isso é importante, mas não corresponde plenamente à realidade brasileira. Em primeiro lugar, a simples adoção de medidas como essas servem para maquiar uma realidade muito mais complexa, que não se resolve construindo nem equipando escolas, muito menos dando cursos de formação tecnológica para professores.

Uma das discussões que se intensificou durante a pandemia foi o homeschooling. Em nível nacional a discussão não parece avançar - de 2001 até 2020 passaram pelo Congresso Nacional diversos projetos de lei relativos ao assunto, e nenhum deles resultou em alterações no Estatuto da Criança e do Adolescente e na Lei de Diretrizes e Bases da Educação Nacional. Atualmente está em discussão o Projeto de Lei 2401/2019, de autoria do Poder Executivo, assinado pela Ministra Damares Alves e pelo ex-Ministro Abraham Weintraub. Este projeto prevê a possibilidade de ensino domiciliar no Brasil, desde que compridos uma série de critérios, entre eles a realização de uma avaliação coordenada pelo Ministério da Educação. Foi enviado em 22/10/2019 pela Mesa Diretora da Câmara dos Deputados às comissões que o discutirão, mas desde então não houveram avanços.

Enquanto isso, a discussão está sendo feita nas Unidades da Federação e em algumas capitais. Esta será, potencialmente, uma das grandes mudanças na educação brasileira nos próximos anos, fortalecida pelas dificuldades que as escolas enfrentam no sentido de conseguir resultados, pela insegurança nas cidades, pelo alto custo de vida e pelo argumento da liberdade de escolha. Estes motivos são acrescidos, em 2020, pelo medo de contágio por Covid-19, uma vez que há indícios de que o vírus permanecerá ativo.

Casagrande e Hermann (2020) explicam que estes argumentos, por si sós, não são suficientes para justificar a necessidade de educação domiciliar. Segundo os autores, a escola tem 
exatamente a função, já afirmada por Durkheim (2013), de socialização. "A interação permite a aprendizagem de estratégias de entendimento acerca de coisas, de fatos e de situações do mundo objetivo, subjetivo e social” (CASAGRANDE; HERMANN, 2020, p. 11). A escola, enquanto espaço especializado em educação, mostra-se necessária, ainda que possa haver socialização em outros ambientes, pois a escola faz as mediações pedagógicas neste processo.

Septimio e Pessoa (2020, p. 143) afirmam que “a liberação da prática do homeschooling, em qualquer de suas modalidades, é prejudicial para a educação brasileira, por se revelar uma prática extremamente elitista frente à realidade do país". De fato, a não ser que se pense em alternativas viáveis, essa modalidade de educação só seria possível para as pessoas mais ricas, enquanto as pobres continuariam estudando em escolas precárias, o que acentuaria a desigualdade educacional e incentivaria a evasão escolar.

Por que, então, isso passa a ser discutido como "uma alternativa em tempos de pandemia" (JÚNIOR; LAUER, 2020)? Uma hipótese é a de que a escola, nos moldes atuais, não atende às expectativas das famílias, nem em termos de conteúdo curricular, nem em nível de exigência ou de resultados. Logo estas, por não se sentirem atendidas, passam a acreditar que é seu direito moldar a educação a seu gosto. Outra hipótese, menos provável, é a de que algumas famílias se acostumaram com o ensino remoto e perceberam que dá para ter aula sem precisar mandar os filhos à escola. Para provar qualquer dessas hipóteses, ou ainda outras, seria necessária outra pesquisa, o que não é o objetivo do presente artigo.

À parte a questão jurídica e a constitucionalidade disso, que está sendo devidamente discutida nos âmbitos legais, parece claro que o homeschooling pode ser a principal mudança na escola nesta primeira metade do século XXI, e que essa mudança tende a se acelerar frente a pandemia de Covid-19. Diante disso surge uma primeira pergunta: como deve ser encarada esta mudança, como revolução ou como retrocesso? É certo que se no Brasil a educação domiciliar fosse regularizada, teria sido uma saída frente à pandemia. Por outro lado, desde que surgiu a educação moderna no século XVII, discute-se a importância da escola como espaço especializado de para a educação.

A segunda pergunta deve ser: como o Estado deve enfrentar o problema? Se, no século XVII, a reinvenção da escola partiu de uma mudança de paradigmas, e desenvolveu, a partir da realidade, uma mentalidade de necessidade social, a nova escola do século XXI pós-pandemia também precisa olhar a realidade e para os paradigmas e perguntar-se sobre a sua identidade. Por isso, as lições da pandemia para a educação vão além da simples mudança no visual. Isso também 


\section{Dialogia}

TREZZI, Clóvis. A educação pós-pandemia: uma análise a partir da desigualdade educacional

é importante, mas deve ser parte de um projeto maior, que tenha por motivação pensar uma escola que seja justa.

\section{A busca por uma escola justa}

O Estado tem, pela Constituição Federal, a prerrogativa de organizar a educação e o dever de ofertá-la a todas as crianças e adolescentes em idade escolar. Contudo, o acesso à educação básica no Brasil está longe de ser universalizado. Logo, o Estado começa falhando ao não conseguir cumprir a própria Constituição.

A legislação brasileira é generosa, mas ao mesmo tempo comedida. Segundo a meta 7 do PNE, os investimentos em educação deveriam alcançar 7\% do PIB em 2019. Em 2005 esse gasto havia sido de apenas 4,5\% (TODOS PELA EDUCAÇÃO, 2020, p. 119). Em termos numéricos, o Brasil pode gabar-se de estar fazendo um alto investimento, superior a muitos países avançados economicamente. Contudo, quando se olha o investimento por estudante, na educação básica, ele está muito abaixo da média dos países membros da OCDE (Organização para a Cooperação e Desenvolvimento Econômico): no ensino fundamental é de US\$3.183/ano, contra US\$ 8.640 na média da OCDE. Já no ensino médio, o inv mergente”. Essa estimento é ainda menor: US\$ 3.835 contra US\$10.017 na média da OCDE (TODOS PELA EDUCAÇÃO, 2020, p. 119).

Para o Brasil tentar se equiparar a outros países melhor avaliados, otimizar os recursos investidos parece ser a primeira e principal tarefa. Dito o óbvio, percebe-se a importância que o país dá a determinado setor pela quantidade de recursos nele alocados e pela maneira como eles são investidos. Para sair da crise gerada pela pandemia sem sequelas maiores, este é o primeiro e principal passo.

Pode-se aqui fazer uma reflexão a partir do dualismo apontado por Libâneo (2012, p. 13): uma "escola do conhecimento para os ricos, escola do acolhimento social para os pobres". Para o autor, "a escola que sobrou para os pobres, caracterizada por suas missões assistencial e acolhedora (incluídas na expressão educação inclusiva), transforma-se em uma caricatura de inclusão social”. (LIBÂNEO, 2012, p. 23).

Considera-se que para uma superação da crise e para focar na possibilidade de a educação não sofrer maiores danos, com o risco do aumento da desigualdade educacional, é preciso que escola passe a ser vista como um espaço de inclusão e não de exclusão.

Como bem aponta Dubet (2004), o simples ingresso na escola não garante a inclusão e muito menos a justiça escolar, pois as desigualdades sociais também devem ser consideradas nesse processo. $\mathrm{O}$ momento crítico da pandemia serviu como alerta ara algo que já se sabia há muito 
tempo: as maiores dificuldades ficam com os mais pobres. Por exemplo: não adianta criar vagas para todos, se 34,3\% das crianças vão para a escola com fome (UNICEF, 2019, p. 5) por não terem dinheiro sequer para comprar os alimentos da cesta básica. Da mesma forma, não adianta estabelecer uma escola tecnológica, se $61 \%$ das crianças e adolescentes não têm acesso à tecnologia em casa por viverem na pobreza (UNICEF, 2019, p. 5).

Há um discurso, por um lado ingênuo e por outro ideológico, de que as crianças do século XXI vivem na era digital e por isso não se adaptam a uma escola analógica. É bem verdade que o paradigma emergente (SANTOS, 1995) neste século tem relação com as questões da tecnologia; contudo, também é verdade que para essas crianças primeiro é necessário pensar em condições mínimas para que possam estudar. São as mesmas crianças que, durante o ensino remoto, não conseguiram apropriar-se dos conteúdos por não terem sequer acesso à internet. Dados da Pesquisa Nacional de Amostra de Domicílio - PNAD Contínua 2020, mostram que 25\% das famílias brasileiras ainda não têm acesso à internet, ou seja, cerca de 50 milhões de famílias.

Portanto, defender uma educação tecnológica como o ideal para o pós-pandemia mostrase utópico. Não que não seja este o futuro da escola. O rumo que a sociedade está tomando mostra que ou a escola se torna digital ou não há espaço para ela. Mesmo assim, seguindo o pensamento de Dubet (2004), há que se pensar na realidade dos alunos sob risco de tornar a escola não apenas injusta, mas excludente.

Outra questão polêmica no Brasil são os baixos resultados educacionais a despeito dos investimentos e de uma Base Nacional Comum Curricular bem estruturada. Para o relatório "Desafios da Nação", do IPEA (Instituto de Pesquisa Econômica Aplicada) (BRASIL, 2018, p. 67), parece não ser a falta de investimentos o problema: “O desempenho do sistema educacional é pífio, mas não faltam recursos financeiros”. Por outro lado, o Plano Nacional de Educação (BRASIL, 2014), ao colocar como vigésima meta "ampliar o investimento público em educação pública de forma a atingir, no mínimo, o patamar de sete por cento do Produto Interno Bruto (PIB) do país no quinto ano de vigência desta lei e, no mínimo, o equivalente a dez por cento do PIB ao final do decênio" mostra que os 5,7\% do PIB investidos em educação pelo Brasil em 2019 não são suficientes. O Anuário Brasileiro da Educação Básica (TODOS PELA EDUCAÇÃO, 2020, p. 119) mostra que enquanto outros países membros da OCDE gastam 50\% a mais com ensino superior em relação à educação básica, o Brasil investe cerca de três vezes mais por aluno do ensino superior: na educação básica o gasto é de $\mathrm{R} \$ 3,8$ mil dólares por aluno/ano, enquanto que no ensino superior é de $\mathrm{R} \$ 14,2$ mil dólares por aluno/ano. 
Merece crítica o olhar puramente quantitativo que muitas vezes tem sido usado para avaliar a escola: a falta de professores é compensada com o fechamento de salas de aula e colocação de 40 ou 50 alunos na mesma sala; o baixo resultado nas avaliações é compensado inserindo-se mais conteúdos na matriz curricular. Embora o Brasil seja muito grande e com diferenças enormes, e exatamente por causa disso, programas de educação que prevejam as mesmas competências e habilidades para todos os alunos também merecem críticas, justamente porque não veem o aluno enquanto indivíduo, mas como estatística.

Uma das características da escola moderna, que se desenvolveu a partir de meados do século XVII, era a preparação para a vida. Mencione-se aqui a compreensão de que a escola tinha um papel social importante -recorde-se que La Salle (2012), que é referência na história da educação moderna, pensou em uma rede de escolas voltadas à educação dos filhos dos trabalhadores, com o argumento de que eles, se não souberem ler e escrever, "nunca serão aptos a emprego nenhum" (LA SALLE, 2012, p. 196) e que um trabalhador, "sabendo ler e escrever, é capaz de tudo" (LA SALLE, 2012, p. 197). Dados da PNAD mostram que um dos principais motivos para o abandono escolar no ensino médio é a necessidade de trabalhar; outro motivo importante é a falta de interesse (IBGE, 2020).

Uma interpretação livre destes dados leva a afirmar que parte dos jovens brasileiros não está encontrando na escola um espaço que os prepare para o trabalho; ou então simplesmente estão sendo excluídos da escola porque percebem que é mais útil trabalhar do que estudar. Curiosamente, lendo La Salle (2012), percebe-se que este mesmo problema já existia no século XVII.

\section{Conclusão: uma escola que mira o futuro}

Olhar para a escola brasileira pós-pandemia significa pensar uma escola que olhe para o futuro. Muitas pesquisas já foram publicadas sobre o impacto sobre a economia e, consequentemente, sobre a população brasileira, de uma escola que não funciona devidamente. A simples eliminação da reprovação e da evasão traria uma economia muito alta ao país.

Não por acaso as desigualdades são tão gritantes. Embora superá-las não seja tarefa exclusiva da educação, esta pode ser um agente tanto no sentido de superação quanto de perpetuação ou ampliação das mesmas. Tudo depende de como o sistema é organizado ou de como é feita a distribuição de recursos ou mesmo de como a situação é encarada.

A pandemia de Covid-19 escancarou uma realidade educacional que já era conhecida. Essa realidade mostrou-se extremamente cruel e desumana, pois, além de acentuar a desigualdade, fez com que muitas famílias, que já passavam privações, economizassem ainda mais para a aquisição 
de equipamentos, ainda que rudimentares, para acessar as aulas remotas. Outros sequer conseguiram. Há que se considerar ainda aquelas crianças que recebiam a alimentação na escola e, de uma hora para outra, perderam o benefício.

A alternativa do homeschooling surge como elitista e disponível para poucos. Além de não substituir as funções da escola, o ensino domiciliar só poderá ser acessado por aquelas famílias que dispõem de muito dinheiro e formação suficiente para levar adiante o projeto pedagógico de formação dos próprios filhos. Estes são, justamente, aqueles que não tiveram problemas durante a pandemia e também não sofrem com a baixa qualidade da educação escolar ou a falta de vagas na escola.

A busca por uma escola justa parece ser a única opção para a educação no momento póspandemia. Embora com atraso de meio século, o primeiro passo a ser dado é compreender como a escola pode ser inclusiva e buscar alternativas para isso. Se a escola justa é não apenas aquela que garante o ingresso - o que já seria um avanço no Brasil - mas aquela que leva em consideração as diferentes realidades para que todos os estudantes possam acessar não apenas a sala de aula, mas os conteúdos curriculares e extracurriculares de acordo com a sua própria condição, aos poucos a escola pode ir se abrindo para os novos paradigmas educacionais.

O impacto e as sequelas deixados pela pandemia de Covid-19 revelam que se a escola continuar se deixando contaminar por ideologias que levam à exclusão, como a falsa ideia de meritocracia, nos próximos anos continuaremos com os mesmos problemas. Antes de pensar em alternativas que mexam na estrutura da escola, é preciso pensar a própria identidade da escola. E, pensando a identidade da escola, pensar na humanização da mesma.

Uma escola justa é uma escola humanizada. Ou a educação pós-pandemia segue esse rumo, ou continuará reforçando a desigualdade e a exclusão.

\section{Referências}

ARIÈS, Philippe. História social da criança e da família. 2. ed. Rio de Janeiro, RJ: LTC, 2015.

BOBBIO, Norberto. A era dos direitos. Rio de Janeiro, RJ: Elsevier, 2004.

BRASIL. Câmara dos Deputados. Plano Nacional de Educação 2014-2024. Brasília, DF: Edições Câmara, 2014. E-book. Disponível em:

https://bd.camara.leg.br/bd/bitstream/handle/bdcamara/20204/plano_nacional_educacao_2014-

2024_2ed.pdf?sequence=13\&isAllowed=y. Acesso em: 20 set. 2020. 


\section{Dialogia}

TREZZI, Clóvis. A educação pós-pandemia: uma análise a partir da desigualdade educacional

BRASIL. Instituto de Pesquisa Econômica Aplicada. Desafios da Nação Vol. 1. Brasília, DF: Ipea, 2018. E-book. Disponível em:

http:/ $/$ www.ipea.gov.br/portal/index.php?option $=$ com content\&view $=$ article\&id $=32753 \& I t e m$ $\underline{\mathrm{id}=433}$. Acesso em: 22 set. 2020.

CASAGRANDE, Cledes; HERMANN, Nadja. Formação e homeschooling: controvérsias. Práxis Educativa, Ponta Grossa, v. 15, e2014789, p. 1-16, 2020. Disponível em: https://revistas.apps.uepg.br/index.php/praxiseducativa/article/view/14789/209209212953. Acesso em: 22 set. 2020.

COMENIUS, Jan Amos. Didática Magna. 4. ed., São Paulo, SP: WMF Martins Fontes, 2016.

DUBET, François. O que é uma escola justa? Cadernos de Pesquisa, São Paulo, SP, v. 34, n. 123, p. 539-555, set./dez. 2004. Disponível em:

https://www.scielo.br/pdf/cp/v34n123/a02v34123.pdf. Acesso em: 25 set. 2020.

DURKHEIM, Émile. Educação e sociologia. 4. ed., Petrópolis, RJ: Vozes, 2013.

FIÉVET, Michel. Les enfants pauvres à l'école: La révolution scolaire de Jean-Baptiste de La Salle. Paris, França: Imago, 2001.

GAUTHIER, Clermont. O século XVII e o nascimento da Pedagogia. In: GAUTHIER, Clérmont; TARDIF, Maurice (orgs.). A Pedagogia: teorias e práticas da Antiguidade aos nossos dias. Petrópolis, RJ: Vozes, 2014, p. 101-127.

HENGEMÜLE, Edgard. Educação Lassaliana: Que educação? Canoas, RS: Salles, 2007.

LA SALLE, João Batista de. Guia das Escolas Cristãs. Canoas, RS: Unilasalle, 2012. Coleção Obras Completas vol. III.

LIBÂNEO, José Carlos. O dualismo perverso da escola pública brasileira: escola do conhecimento para os ricos, escola do acolhimento social para os pobres. Educação e Pesquisa, São Paulo, SP, v. 38, n. 1, p. 13-28, 2012. Disponível em: http://www.scielo.br/pdf/ep/v38n1/aop323.pdf.Acesso em: 10 set. 2020.

MANACORDA, Mario Alighiero. História da educação: da antiguidade aos nossos dias. 13. ed., São Paulo, SP: Cortez, 2010.

IBGE. Educação 2019 - PNAD Contínua. Disponível em: https://biblioteca.ibge.gov.br/visualizacao/livros/liv101736_informativo.pdf. Acesso em 24 set. 2020.

JUNIOR, Jerri Garcia da Rosa; LAUER, Pedro. Homeschooling como alternativa em tempos de pandemia. Anuário Pesquisa E Extensão Unoesc São Miguel Do Oeste, v. 5, pp. 1-14, e24585, 2020. Disponível em:

https://portalperiodicos.unoesc.edu.br/apeusmo/article/view/24585/14456. Acesso em: 22set. 2020.

SANTOS, Boaventura de Sousa. Um discurso sobre as ciências. 6. Ed., Porto: Afrontamento, 1995. 
SEPTIMIO, Carolline; PESSOA, Márcio de Souza. O ensino domiciliar como política pública no Brasil: uma alternativa às escolas? Olhares, Guarulhos, v. 08, n. 02, pp. 133-146, 2020. Disponível em: https://periodicos.unifesp.br/index.php/olhares/article/view/10777/7894. Acesso em: 22 set. 2020.

TODOS PELA EDUCAÇÃO. Anuário Brasileiro da Educação Básica 2020. São Paulo, SP: Moderna, 2017. E-book. Disponível em:

https://www.todospelaeducacao.org.br/_uploads/_posts/456.pdf?1969753478/=\&utm_source $=$ content\&utm_medium $=$ site-todos.Acesso em: 20 set. 2020 .

UNICEF. Pobreza na infância e na adolescência. Unicef, 2019. Disponível em: https://www.unicef.org/brazil/media/156/file/Pobreza_na_Infancia_e_na_Adolescencia.pdf. Acesso em: 24 set. 2020. 